\title{
MONSTRO ÍNTIMO: O PROBLEMA CONTEMPORÂNEO DO OBJETO ATRAVÉS DOS QUADRINHOS DE CHARLES BURNS
}

\author{
THE INTIMATE MONSTER: THE CONTEMPORARY PROBLEM OF THE \\ OBJECT THROUGH CHARLES BURNS COMICS
}

Alexandre Linck Vargas

Universidade do Sul de Santa Catarina

\begin{abstract}
Resumo: Sejam raças fabulosas que vivem nos confins da terra, sejam seres individuais na fronteira entre o animal e o divino, o monstro é o Outro. Porém, pela obra do quadrinista Charles Burns, sobretudo a trilogia Last look, e o rastro que nele advém, a experiência pelos quadrinhos do pós-guerra inscrevem na contemporaneidade uma outridade não exterior, não objetal, um monstro íntimo. Busca-se, então, a partir de autores como Julia Kristeva e Peter Sloterdijk, com os conceitos de abjeto e nobjeto, respectivamente, pensar o espaço íntimo de transmissão do sujeito, do vir-a-ser-sujeito monstruoso. Uma questão estética que, da psicanálise à esferologia, apontará ao interior ocupado pelo monstro no contemporâneo.
\end{abstract}

Palabras-chave: Monstro, Intimidade, Quadrinhos, Abjeto, Nobjeto.

Abstract: Whether they are fabulous breeds that live on the ends of the earth, whether they are individual beings on the threshold between the animal and the divine, the monster is the Other. However, through the work of the comic book writer Charles Burns, especially the Last look trilogy, and the traces in it, the experience of the postwar comic strips inscribe in contemporaneity a non-external non-object otherness, an intimate monster. Therefore, it is sought, from authors like Julia Kristeva and Peter Sloterdijk, with the concepts of abject and nobject, respectively, to think the intimate space of transmission of the subject, of the monstruous becoming-subject. An aesthetic question that, from psychoanalysis to spherology, will point to the interior occupied by the monster in the contemporary.

Keywords: Monster, Intimacy, Comic books, Abject, Nobject. 
O monstro é o Outro. Sejam as raças fabulosas que vivem na fronteira, para além da fronteira, no além-mar e mundo, sejam as aberrações individuais entre nós, que conformam-se à uma outridade animal ou divina, sempre um passo aquém ou além da identidade em que me encontro. "Assim, os monstros não são apenas fisicamente ameaçadores, são cognitivamente ameaçadores. São ameaças ao saber comum”. (CARROLL, 1999, p. 53). Ou seja, a ameaça que o monstro representa, a representação que ele faz a vez, desestabiliza o saber que o ver e o pensar seriam capazes de articular. Isso nos conduziria ao entendimento de que a outridade do monstro é o exterior do humano, o lado de fora insuportável da humanidade.

Esse raciocínio, porém, não encontra correspondência na arte dos quadrinhos. Pelo contrário, a partir do pós-guerra, o monstruoso nas histórias em quadrinhos é tratado menos por uma repulsa, distância ou exterioridade pura, e mais pela proximidade, intimidade, fazendo do monstro o habitante de um espaço interior. A bem da verdade, a literatura e o cinema farão algo semelhante. Contudo, conforme veremos, há diferenças na formação histórica dos quadrinhos que fizeram do monstro um "algo íntimo". Ademais, é possível afirmar que tanto o cinema quanto a literatura de monstros próximos não poderiam chegar onde chegaram sem a conciliação ocasionada pelos quadrinhos. Pensar o monstruoso por sua exterioridade mostrase um equívoco na medida em que se assenta na relação sujeito e objeto, homem e monstro, como se essa fosse uma condição universal. Por consequência, ignora-se a historicidade de uma relação sujeito e objeto, além de negligenciar as complexas macro e microesferas humanas nas quais os monstros ocuparam um espaço interior. "O monstro não se situa fora do domínio humano: encontra-se no limite" (GIL, 2006 p. 14).
Vira-se a página. 0 monstro íntimo expõe-se. Tratam-se dos trabalhos de Charles Burns, principalmente a trilogia Last look, projeto iniciado em 2010 e concluído em 2014. Objetiva-se abordar nas HQs de Burns sua contemporaneidade, isto é, "uma relação singular com o próprio tempo, que adere a ele e, ao mesmo tempo, toma distância dele" (AGAMBEN, 2015, p. 22). Esse procedimento de dissociação e anacronismo, capaz de articular as urgências do arcaico no moderno, é o que possibilita ao artista contemporâneo "não se deixar cegar pelas luzes [...] e distinguir nelas a parte da sombra, a sua íntima obscuridade" (Idem, p. 26). É através dessa íntima obscuridade, por tempos complexos, que a monstruosidade será estudada em um artista costumeiramente chamado de quadrinista de horror, mas, para o próprio, é somente alguém que faz histórias de amor (VITRAL, 2018).

\section{Abjeto}

A trilogia Last look, compilada em 2016, é composta dos episódios X'ed out (2010), The hive (2012) e Sugar skull (2014). A narrativa centrada no adolescente, e posteriormente jovem adulto Doug, é fragmentada, cabendo ao leitor costurar os tempos e espaços. Isso, porém, na maior parte, não escapa da estrutura de uma história de mistério, subsistindo uma propositalmente oculta trama governante que terá contornos mais claros ao final do último episódio. Uma exceção a isso, parcial, pois ela também auxilia na resolução do mistério, ainda que esteja lá mais enquanto comentário do próprio segredo, é o mundo imaginário do protagonista. Contudo, Burns, com bastante virtuose, e aproveitando-se da forma das HQs, faz uso de pontos de ligação, comuns numa história de mistério sob o jogo "ligue os pontos", de modo a estabelecer uma rede de conexões bastante sofisticadas não só no interior da HQ, mas ex- 
ternamente a ela. Deste modo, os pontos, ou melhor, os quadros, intensificam-se, proliferam significados, e fazem do próprio mistério não um funil para onde a trama converge, mas uma sobreposição, multicamadas de mistérios que não se esgotam em revelações.

Doug é um jovem artista do final dos anos 1970. Presente no cenário musical punk, sua performance consiste em, antes das apresentações musicais, ir ao palco mascarado sob o pseudônimo de Johnny 23 e, enquanto toca no último volume uma fita composta de sons aleatórios como retorno da guitarra, comerciais de televisão, ruído branco etc, ele lê cut-ups. 0 estranhamento é geral, e frequentemente ele é interrompido, porém, Doug acaba tornando-se uma figura reconhecida localmente. Sua performance transita da cultura Beat ao dadaísmo, de William Burroughs a Tristan Tzara, e assim ele a faz sob a máscara do personagem Nitnit. No mundo de Last look, Nitnit é o Tintin, de Hergé: o rosto redondo, o pequeno nariz, olhos pontuados e o famoso topete. É no mundo de Nitnit que adentramos quando o mundo imaginário de Doug ganha vez. Diferentemente das histórias do quadrinista belga, o mundo de Nitnit é opressivo, sombrio e povoado de monstros. Em comum, apenas o espírito aventureiro da história, ainda que, na ordem das motivações, Nitnit atue mais pela força das circunstâncias do que por uma vontade alegre, comum em Tintin. A sombra de Hergé, contudo, se expande, com cada episódio da trilogia Last look composto com o mesmo formato e número de páginas de um tradicional álbum franco-belga.

É algo inusitado a monstruosidade pedir passagem a partir do imaginário de Hergé. Nitnit chegou a esse mundo monstruoso de maneira um tanto carrolliana. Em seu quarto, diante de um buraco na parede, ele avistou Inky, o seu falecido gato. Estranhando a aparição, seguiu -o, passando por uma rede de esgotos e um estoque de ovos, e chegou ao mundo de onde jamais voltaria a sair. O convite à aventura decorreria da necessidade de viver nesse mundo, ganhar o próprio dinheiro e alimentar-se da asquerosa comida, além de aproximar-se da bela moça, a nova rainha, que ele avistou sendo conduzida com honrarias para a Colmeia. No mundo de Nitnit, uma terra arrasada composta de clichês do oriente médio e do deserto mexicano, existem lagartos humanoides engravatados, todos extremamente impacientes e grosseiros, e um sistema no qual mulheres poedeiras são mantidas confortavelmente aprisionadas para alimentar a população com ovos. O complexo no qual essas mulheres são mantidas chama-se a Colmeia. Chamado pelos outros personagens de Johnny, Nitnit é guiado por um homem que se assemelha a um bebê envelhecido, ele é baixinho, com uma pequena mochila nas costas e veste apenas o que parece uma fralda branca e tênis. A comida é repulsiva, muitas vezes está viva e evidencia o desespero que é ser devorada, o que embrulha o estômago de Nitnit. Também há outras etnias monstruosas, que falam um idioma desconhecido a Nitnit, sempre em pequenos comércios ou mendicância.

É preciso sublinhar que o verbo latino monstrare significa muito menos mostrar um objeto do que ensinar, advertir, condenar, prescrever uma via a seguir. Por consequência, o substantivo monstrum, como um portento, sinal, advertência dada pelos deuses, acaba por nos remeter menos a um objeto e mais a um percurso, um caminho, um sentido que, ele próprio, é fugidio devido a costumeira fala cifrada dos deuses (GIL, 2006). Portanto, etimologicamente, uma falta de objetividade subjaz o monstro. Essa consideração pode vir a ter grandes consequências, pois possibilita, ao mesmo tempo, historicizar a objetificação do monstro e ensejar um tratamento não-objetal. 
Para contrapor ao objeto, uma alternativa seria o conceito de abjeto de Julia Kristeva. O abjeto é "aquilo que perturba uma identidade, um sistema, uma ordem. Aquilo que não respeita os limites, os lugares, as regras. O intermediário, o ambíguo, o misto." (KRISTEVA, 1980, p. 12). Para Kristeva, a abjeção retoma a noite arcaica, na qual o corpo que cai, a criança que vem à luz, torna-se ela própria abjeta pela separação. Depois que o Outro (o simbólico, a linguagem) possui-a como o alter ego, retorna-se à abjeção por meio da pulsão, ou melhor, da ex-pulsão, expulsão de si. Daí que o abjeto dá sinais apenas em uma crise narcísica, quando os objetos são opressivos ou precários demais.

Contudo, esse retorno não é capaz de desativar a repulsa, pois ela é constitutiva dos limites do eu, cabendo ao Outro, tornado alter ego, deixá-la recair na condição fronteiriça abjetal, sem nela se perder. É a partir dessa circunstância, sempre intervalar e repetitiva, proibida e tentadora, que se produz a repugnância. "Nesse sentido, somente o gozo faz com que o abjeto exista como tal. Não se pode conhecê -lo, não se pode desejá-lo, só se pode gozá-lo. Violentamente e com dor." (Idem, p. 17). A repressão primária proposta por Kristeva prontamente atualiza-se no bebê que repele o leite da mãe, corpo que a sustém mas que igualmente deve ser no devido momento afastado, corpo atraente e vetado, e por isso mesmo repugnante. Portanto, o abjeto instaura uma condição de afeto e perigo constante, anterior ao significado, no qual aquilo que nos envolve e protege é também nossa fonte de ameaça, já que as distinções entre eu e outro, dentro e fora, vida e morte, ganham ali sua condição de passagem.

Se coube às religiões, a partir do sagrado, purificar-se do abjeto, com a crise imposta pela modernidade, restou à arte esse acertar de contas:
Em um mundo em que o Outro se encontra caído, o esforço estético - descida às fundações do edifício simbólico - consiste em retratar as fronteiras frágeis do ser falante, ao mais próximo de sua alvorada, dessa "origem" sem fundo que é a repressão originária. Nessa experiência conduzida doravante pelo Outro, "sujeito" e "objeto", repelem-se, afrontam-se, desmoronam-se e recomeçam, inseparáveis, contaminados, condenados, no limite do assimilável, do pensável: abjetos. A grande literatura moderna desdobra-se sobre tal terreno: Dostoievski, Lautréamont, Proust, Artaud, Kafka, Céline... (KRISTEVA, 1980, p. 25).

Podemos acrescentar Charles Burns como um dos netos dessa geração. Antes de Last look, Burns debruçaria-se na abjeção emergente pela sexualidade de jovens da Seattle de meados dos anos 1970. Publicada em 12 edições, entre 1994 e 2005, e posteriormente reunida em um único volume, Black hole é o trabalho mais premiado de Burns, e possui como cifra de leitura mais comum a alegoria da puberdade. Todavia, é preciso ir mais longe. Na história o "Bug”, DST que faz o portador desenvolver mutações grotescas, serve, para além de qualquer cartilha preventiva ou terror paranoide, que os personagens redescubram seus corpos, encontrem novas maneiras de erotização, num caminho que leva, pela ambiguidade gráfica (a cauda que é pênis, a segunda boca que é uma vagina etc), à um exílio de si, expulsão da sociedade e da própria identidade. O "buraco negro", portanto, torna-se a sombra do retorno e o lugar de encontro sempre fugaz do abjeto, do qual apenas se goza com repugnância ao longo de toda a HQ.

Contudo, se essa leitura de forte carga psicanalítica nos dá a ex-pulsão do eu, no limiar do sujeito/objeto, ela não necessariamente responde à intimidade para com o monstruoso. Em outras palavras, não há nada a rigor que afirme o monstro enquanto abjeto. A pergunta, então, 
reformula-se: se o monstro fosse abjeto, poderia ser ele para nós uma presença tão cara, tão facilmente domesticável, ora íntima? Na medida em que o abjeto situa-se na fronteira, o monstro jamais poderia encontrar abrigo do lado de dentro. O conceito de semblante lacaniano poderia vir em socorro e, deste modo, o monstro seria o discurso aproximado, o ser para a linguagem, de um real abjeto, que a linguagem não encerra. Porém, o abjeto não é o impossível do real, entendimento este que suprimiria sua condição intervalar. O abjeto, mesmo estando às portas do que não cessa de não se escrever, ele próprio ainda é também um semblante, possibilidade limite do gozo. "O gozo só se interpela, só se evoca, só se suprema, só se elabora a partir de um semblante, de uma aparência" (LACAN, 2008, p. 99). Retornamos, então, ao problema inicial. Para sair do impasse, será necessário retroceder mais.

\section{Objeto}

O cânone da literatura gótica é composto de monstros fascinantes, figuras abjetas situadas no limiar entre o atrativo e o proibitivo. Mary Shelley, Bram Stoker, Robert Louis Stevenson, Oscar Wilde, Edgar Allan Poe, H. P. Lovecraft. Com todo o risco que generalizações desse porte incorrem, pode-se dizer que, até meados do século XX, a narrativa de monstro não parece inclinada a fazer da monstruosidade uma companheira íntima. Pelo contrário, o monstro é o outro, radicalmente outro, ainda que seja, repugnantemente, eu mesmo. Drácula é um ser de outra natureza, porém a vitalidade que ele rouba, com asco, seduz-nos; o monstro de Frankenstein é, na mimese mecânica da vida, o mesmo do doutor que então se percebe outro; Mr. Hyde é outro desgovernado e possessivo do Dr. Jekyll; O retrato de Dorian Gray é o rastro material do outro que precisa ser afastado a todo momento; os contos de crime e mistério de Allan Poe por vezes impõem uma fantasmática na qual mesmo um vil ato ordinário torna-se extraordinário, e um sujeito qualquer precipita-se, não sem tensão, numa condição outra; os mitos de Cthulhu fazem o incomensuravelmente outro colidir-se com o mesmo em regiões fronteiriças da experiência humana. Existe um teor confrontativo na monstruosidade que não interessa a esses escritores distensionar.

Isso, porém, depara-se com um novo paradigma no pós-guerra. Uma geração de crianças e adolescentes que cresceram sob as imagens dos horrores da guerra estavam alegremente consumindo quadrinhos de crime e mistério. Desde que a HQ passou a ocupar-se da infância no início do século XX, ela era partilhada por adultos (no caso dos jornais nos EUA), ou sua destinação à criança em muito passava pelo crivo de um adulto (caso das revistas ilustradas franco-belgas e brasileiras). Mas isso em muito mudaria a partir dos comic books - as revistas em quadrinhos, também chamadas no Brasil, por causa da publicação do grupo Globo, de gibis. Surgidos nos EUA da Grande Depressão, com a precursora The funnies, de 1929, as revistas, que, em muitas ocasiões, editavam materiais previamente publicados nos jornais, passaram a cada vez mais produzir conteúdo original no decorrer dos anos 1930. Por causa do baixo preço, eram acessíveis não só para as crianças, mas também para adultos empobrecidos e desocupados com tempo ocioso (GABILLET, 2010; JONES, 2006).

Passada a era de ouro dos super-heróis durante a segunda guerra mundial, começou, no pós-guerra, a fazer grande sucesso entre os jovens os quadrinhos de crime, horror e mistério. A EC comics, reformulada por Bill Gaines, iria, a partir na primeira década dos anos 1950, lançar títulos como Tales from the crypt, The vault of 
horror e The haunt of fear. Eram revistas populares, com histórias fechadas de poucas páginas, sempre trazendo finais surpresas e a introdução e conclusão por um anfitrião - respectivamente, the Crypt keeper, the Vault keeper e the Old witch. O horror, por sua vez, não era brando, recorrendo à violência explícita, asco e não rara erotização da mulher em perigo de morte. A agressividade gráfica e temática tinha por contraponto uma atenção bastante afetuosa para com os leitores. A EC foi pioneira com as cartas ao editor, fã-clube, reconhecimento autoral dos artistas e a produção de suas biografias que por comentários leves procuravam aproximá-los do leitor (BEATY, 2012).

Essa intimidade entre crianças e monstros sem a tutela dos pais, da escola ou da igreja, junto do crescente número de casos de delinquência juvenil, iria alimentar as campanhas antiquadrinhos no mundo, o que culminaria, em 1954, no Comics Code Authority e o fim dos quadrinhos de monstros íntimos nos EUA. Isso teria efeito em boa parte do globo, já que desde o pós-guerra os quadrinhos estadunidenses haviam se disseminado sem maior concorrência. No Brasil, a escassez do material da EC ajudou a fomentar a produção nacional de crime, horror e mistério, porém o código de censura brasileiro de 1961 foi igualmente destrutivo e com o agravante de inviabilizar editoras dedicadas aos quadrinhos nacionais, como La Selva e Outubro (LINCK VARGAS, 2015). O legado da EC, contudo, seria retomado nos anos 1960, fosse artisticamente, com sua herdeira direta, a Warren Publishing e as magazines Creepy e Eerie, e seus respectivos anfitriões Uncle Creepy e Cousin Eerie, fosse com a dedicação para com o leitor, de modo que os monstros fossem para ele um companheiro íntimo, caso da primeira Marvel comics e super-heróis como o Coisa, Hulk ou mesmo o execrável Homem-aranha. Soma-se a isso toda uma reconsideração política e acadêmica da EC pelos assuntos polêmicos de que tratou, a censura que sofreu e sua valorização do artístico nos quadrinhos, algo que impulsionará a republicação continuadamente desses materiais. É nesse rastro, simultâneo à sua juventude, que Charles Burns forjará seu traço.

Ainda nos 1980, na revista Raw de Françoise Mouly e Art Spiegelman, Burns faria seu tributo mais direto à EC com a série Big baby. A história que aparenta se passar nos anos sessenta mostra uma série de eventos terríveis acontecendo à volta do menino Tony, um garoto comum, bastante imaginativo e amante de ficções de horror. Burns contrasta a simplicidade do garoto de feições estranhas, monstruosas até, com as pessoas à sua voltas, essas desenhadas de maneira mais naturalista, porém com reações atípicas, como se elas tomassem parte de um terrivel mistério que nos escapa. Tanto em Big baby quanto em Black hole, utiliza-se de uma decupagem clássica, o preto e branco de alto contraste e o jogo de luz expressionista, o que remete aos quadrinhos da EC e da Warren. Já na trilogia Last look, a adoção do colorido e a utilização de luzes mais naturalistas amenizam o rastro cinquentista, principalmente transfigurado pelo traço de Hergé, porém ele ainda está lá, ele urra. Nota-se a esfera do horror na passagem em que Doug está isolado, recuperando-se de uma lesão na cabeça e viciado nas drogas do falecido pai - informação esta que demoramos a entender, dada às suas aparentes interações no quadro a quadro. O pai, na maior parte das vezes, senão em todas, é um fantasma mnêmico, deslocado, surgindo inclusive no mundo de Nitnit quando este o encontra de passagem. De maneira ainda mais espantosa, porém, é o amor de Doug por Sarah, quem ele conhece através de uma exposição fotográfica em um edifício abandonado no qual há uma série de fotos dela 
nua e amarrada. Por meio de uma precária escada em um lado escuro da exposição, Doug sobe como se fosse encontrar um monstro. No sótão, sem uma viva alma, há um altar, com uma foto ampliada de Sarah, nua, segurando o filhote morto de um porco contra o seu seio. Ela está cabisbaixa, passa certa melancolia. No altar, por sua vez, está o filhote de porco num pote em conserva.

Conforme Doug e Sarah namoram, mais o gesto horrendo, a imagem transfigurada, a aberração sensível, acabará por mostrar-se pela via artística, como o lugar de encontro entre ambos. Ainda na primeira ocasião que os dois passam a noite conversando, Doug pede para tirar uma foto de Sarah e ela então faz um corte superficial no antebraço com uma lâmina. 0 traço vertical de sangue irá atrair Doug a ponto de se tornar, para ele, uma hipnotizante torrente escura. Mais adiante, conforme Sarah apresenta seus livros e recortes para Doug, este fascinase pela Femme-Maison de Louise Bourgeois, e pede que Sarah pose para incontáveis fotos com uma casa de papelão na cabeça. Depois, na casa de Doug, Sarah pede para que ele se vista como seu pai e experimente os remédios que ele usava. Enquanto estava travestido e inconsciente, Sarah tirou diversas fotos de Doug, o que os fez brigarem seriamente pela primeira vez. Por fim, quando a relação dos dois já estava desgastada, com Sarah grávida e não querendo abortar, Doug conseguiu um coração semelhante ao humano e pediu que Sarah posasse nua, o segurando com uma faca atravessada. Doug sente atração por imagens de Sarah passiva, ferida, desfigurada, inclusive quando se depara com as fotos que ela tirava com o ex-namorado praticando bondage. Ele se diz enojado, porém logo depois insiste a contragosto dela para que transem. Diferentemente, ele não vê qualquer interesse no prazer que Sarah tem na leitura de quadrinhos românticos dos anos 1950 e 60, objetos também alvo da censura antiquadrinhos. Nessas histórias de moças apaixonadas e lamuriosas, Sarah vê uma beleza a ponto de gracejar situações semelhantes com Doug.

Seja na proximidade dos corpos, seja no abismo entre os espíritos, em Last look a todo momento é o monstruoso que, do mundo imaginário de Doug à experiência artística do casal, acena com figuras de contato íntimo. Mais do que isso, o monstruoso mostra-se como a única possibilidade. Inclusive no final, quando descobrimos que Sarah teve o filho que Doug nunca assumiu, este ao tentar se reaproximar, fá-lo no dia das bruxas. Sarah voltava com seu filho, fantasiado, a quem pede que tire a máscara - o rosto do próprio filho que nunca havia visto não parece afetar Doug. Com o garoto na varanda, a conversa não corre bem. Doug foi ausente por tempo demais, não há mais o que consertar. No fim da conversa, porém, Doug perde a atenção para retornar ao mundo de Nitnit. "I'm not listening. I'm not even here." (BURNS, 2016, s/n). Diferentemente do cânone da literatura gótica, não há a confrontação de um monstro. Mais difícil ainda falar de abjeção, quando a repugnância torna-se protocolar, previsível, como um gesto antigo que perdera o sentido nas mãos de um feioso anfitrião. Destarte, o que o monstro etimologicamente adverte, o que encaminha misteriosamente no rastro de Burns é o espaço íntimo de transmissão de um sujeito, de um vir -a-ser-sujeito monstruoso.

\section{Nobjeto}

Os exemplos literários de abjeto no ensaio de 1980 de Kristeva são quase todos personagens anteriores à segunda guerra. Da mesma maneira, a abjeção parece adequar-se com maior ou menor precisão aos monstros da literatura gótica canônica. Porém, conforme vimos, existe 
uma mudança de percepção no pós-guerra que as história e a estética das HQs demonstram. A abjeção torna-se inadequada para abordar a animada comunhão com um monstro íntimo. Cabe, portanto, na fronteira do abjeto, isto é, no limiar dentro/fora, voltarmo-nos para dentro, recapitular a interioridade pura. Recorramos à esferologia de Peter Sloterdijk, na qual ele toma emprestado de Thomas Macho o conceito de nobjeto para se referir à "entidades dadas de maneira esfericamente envolvente que, ao modo de presença não confrontativa, planam como seres originários de proximidade, no sentido literal do termo, diante de um si que não Ihes faz face, precisamente o pré-sujeito fetal" (SLOTERDIJK, 2016, p. 270). O nobjeto serve à Sloterdijk para formular uma ginecologia negativa ou filosófica, permitindo-o esquivar-se de significantes como placenta, feto e útero, e pensar a bolha coexistencial íntima arcaica, na qual o acompanhante originário, o Com, está ali, próximo do Também. "O Com funciona, assim, como um guia íntimo para o Também-Si” (Idem, p. 322). Esse espaço, no qual um nobjeto comunica um aqui enquanto sujeito, um vir-a-ser sujeito, ou mesmo, numa expressão negativa equivalente, um (N)Ego, irá se metamorfosear ao longo da vida psíquica e sensível do sujeito, com o acompanhante originário assumindo diferentes nomes públicos. "No interior da bolha, o êxtase, o estar ao lado de outro, é a situação normal; como a bolha é o lugar absoluto, ao estar nela - e, nela, no outro polo -, sempre estou em meu lugar." (Idem, p. 399).

A esferologia de Sloterdijk postula uma coexistência que precede a existência. Da mesma maneira, encurrala historicamente o conceito de indivíduo do século XVII e XVIII, tanto numa filosofia na natureza mecânica do homem para quem o outro é o exterior, quanto no dualismo cartesiano res cogitans/res extensa que fará sombra inclusive na relação sujeito/objeto da psicanálise freudiana. Daí a recusa de Sloterdijk por qualquer ideia de "relação" quando quer pensar a bipolaridade microesférica, pois não existe na bolha nada como um objeto descartável ou um sujeito autônomo, nem mesmo uma relação a posteriori. Assim sendo, o sujeito, quando alijado do nobjeto, torna-se melancólico, mas poderá restituí-lo de três formas: pela religião, pela terapia ou - essa aqui nos interessa especificamente - pela mídia, isto é, por técnicas de autocomplementação.

Mas onde, como no período moderno mais recente, o Co-espaço é anulado e confiscado desde o início pela destruição da placenta, o indivíduo regressa cada vez mais aos coletivos maníacos e às mães totais - e, na falta desses, à depressão. A partir daí, o indivíduo, sobretudo masculino, tende a mergulhar cada vez mais fundo na alternativa fatal entre o desafio autístico de isolamento e o deixar-se engolir pelas comunidades obsessivas - a dois ou a muitos. (...) Se o indivíduo não consegue se completar e se estabilizar por meio de aplicações bem-sucedidas das técnicas de solidão - por exemplo, nos exercícios artísticos e solilóquios escritos -, ele está destinado a ser absorvido pelos coletivos totalitários (SLOTERDIJK, 2016, p. 349).

Em Last look, o mundo de Nitnit, refúgio imaginário e artístico de Doug, o qual ele aparece em determinado quadro o lendo, está submetido ao que dá todos os sinais de ser um regime totalitário. Da mesma forma, quando Doug é espancado pelo ex-namorado de Sarah e passa um tempo em recuperação, ele se torna paranoico, e, inclusive, não encontra forças para responder às incontáveis tentativas de contato dela a avisar do prosseguimento da gravidez. Um elemento importante é o chamado do interfone/campainha, que surge inicialmente quando Doug é ameaçado pelo ex-namorado de Sa- 
rah, mas também reaparece nas tentativas dela de falar com ele em sua clausura; essa imagem iria se repetir no mundo de Nitnit, às vezes como um cano escorrendo sangue, ou mesmo quando Doug, após a recusa de Sarah em participar da vida de seu filho, retorna ao exílio imaginário e, no último quadro da $\mathrm{HQ}$, nota a campainha tocando novamente. Sloterdijk comenta a aliança sonosférica entre a mãe e a criança como uma das primeiras formas de metamorfose do elo umbilical com a placenta. "A partir da visitação auditiva, o sujeito é conduzido a si mesmo” (Idem, p. 447). Diante de Doug existe um algo que está ali, comunicando, transmitindo. Podese argumentar que foi uma experiência traumática as ameaças por interfone do ex-namorado de Sarah, ou mesmo especular que Doug teria algum problema com a figura materna, mencionada ao longo da história mas que nunca aparece. Porém, a rigor, em todo o tempo ele só foi capaz de corresponder a qualquer sorte de apelo íntimo quando este aderiu em Sarah pelo monstruoso. Nem mesmo o entre rostos, esfera íntima de animação, parece conseguir estabelecer esse elo. O rosto do filho nunca antes visto foi menos tocante do que Sarah com uma casa no lugar da cabeça. Portento, alerta, percurso. Em Last look, o Si somente liga-se ao Com, ele só está Consigo, quando monstruoso.

Trata-se, então, a partir dessa leitura nobjetal do monstro acertar as contas com o rastro de Burns, fazer ver a potência da "íntima obscuridade" de que falava Agamben. Sloterdijk dirá, ao final de Esferas I, já dando passagem para o Esferas II, que a modernidade habita o monstruoso. Ele indaga: "onde estamos quando estamos no monstruoso?” (Idem, p. 567). De certo modo, o monstruoso sempre fez parte das macroesferas, fossem povos fabulosos e estrangeiros que viviam à nossa volta, fossem seres individuais no intervalo cosmo-esférico entre o divino e o animal. Se hoje eles nos parecem exteriores, é porque muitos partiram para o exílio após Descartes, e ao indivíduo pesou o fardo "completate a ti mesmo" (GIL, 2006; SLOTERDIJK, 2016). Contudo, cabe estar atento às sobrevivências, pensaria Aby Warburg. Quando Burns faz ver esse monstro nobjetal, próximo, possibilidade única do vir-a-ser-sujeito, e o faz pela imagem dos quadrinhos do pós-guerra, estes intimamente ligados à infância, ele acaba por traçar a inelutável estética da catástrofe. Difícil não trazer à tona a crise da experiência benjaminiana e leitura de Susan Buck-Morss em Estética e anestética (2012), na qual está o alerta de que para uma cultura banalizada a choques não deveria requerer imagens mais fortes, mas sim restituir a sensibilidade da visão. As revistas em quadrinhos foram por décadas as companheiras solitárias de crianças diante de crises econômicas, regimes autoritários, efeitos das guerras e a insegurança generalizada por uma esfera impossível bipartida em dois blocos políticos. Diante disso, como não pensar que o sensível, o único rescaldo passível de restituição, seria aquele que faz do monstruoso sua esfera íntima? Por isso, uma resposta à Sloterdijk, para tantas as que são possíveis, seria: quando estamos no monstruoso estamos lendo um gibi.

\section{Referências}

AGAMBEN, Giorgio. O que é contemporâneo? In:___. Nudez. Belo Horizonte: Autêntica, 2015.

BEATY, Bart. Comics versus art. Toronto: University of Toronto, 2012.

BUCK-MORSS, Susan. Estética e anestética: uma reconsideração de A obra de arte de Walter Benjamin. In: BENJAMIN, Walter et al. Benjamin e a obra de arte. Rio de Janeiro: Contraponto, 2012.

BURNS, Charles. Big baby. 3a ed. Seattle: Fantagraphics, 2013. 
__. Black hole: introdução à biologia. São

Paulo: Conrad, 2007

Black hole: o fim. São Paulo: Conrad, 2008.

. Last look. Nova York: Pantheon, 2016.

CARROLL, Noël. A filosofia do horror ou paradoxos do coração. Campinas: Papirus, 1999.

GABILLIET, Jean-Paul. Of comics and men: $a$ cultural histort of american comic books. Jackson: University of Mississippi, 2010.

GIL, José. Monstros. Lisboa: Relógio D’água, 2006.

JONES, Gerard. Homens do amanhã. São Paulo: Conrad, 2006.

KRISTEVA, Julia. Approach de la abjection. In: . Pourvoirs de l'horreur: essai sur l'abjection. 6a ed. Paris: Éditions du Seuil, 1980. p. 7-39. Tradução de Allan Davy Santos Sena. Disponível em: <https://www.academia.edu/18298036/Poderes_do_Horror_de_Julia_Kristeva_Cap\%C3\%ADtulo_1>. Acesso em: 22 jul 2018.

LACAN, Jacques. Seminário, livro 20: mais ainda (1972-1973). 3. ed. Rio de Janeiro: Zahar, 2008.

LINCK VARGAS, Alexandre. Essas horríveis histórias em quadrinhos. In: JORNADAS INTERNACIONAIS DE HISTÓRIAS EM QUADRINHOS, 3, 2015, São Paulo. Anais eletrônicos. Disponível em: <http://www2.eca.usp.br/anais2ajornada/ anais3asjornadas/artigos.php?artigo=artigo_060620150941432.pdf>. Acesso em: 22 jul 2018.

SLOTERDIJK, Peter. Esferas I: bolhas. São Paulo: Estação Liberdade, 2016.

VITRAL, Ramon. Papo com Charles Burns, o autor de Black Hole e da trilogia Sem Volta. 2018. Disponível em: <https://www.vitralizado.com/ hq/papo-com-charles-burns-o-autor -de-black -hole-e-da-trilogia-sem-volta/>. Acesso em: 22 jul. 2018. 